\title{
Mass transport of contaminated soil released into surface water by landslides (Göta River, SW Sweden)
}

\author{
G. Göransson ${ }^{1,2}$, M. Larson ${ }^{2}$, D. Bendz ${ }^{1}$, and M. Åkesson ${ }^{3}$ \\ ${ }^{1}$ Swedish Geotechnical Institute, 58193 Linköping, Sweden \\ ${ }^{2}$ Department of Water Resources Engineering, Lund University, 22100 Lund, Sweden \\ ${ }^{3}$ Department of Earth and Ecosystem Sciences, Lund University, 22362 Lund, Sweden
}

Correspondence to: G. Göransson (gunnel.goransson@swedgeo.se)

Received: 12 October 2011 - Published in Hydrol. Earth Syst. Sci. Discuss.: 6 December 2011

Revised: 11 May 2012 - Accepted: 4 June 2012 - Published: 5 July 2012

\begin{abstract}
Landslides of contaminated soil into surface water represent an overlooked exposure pathway that has not been addressed properly in existing risk analysis for landslide hazard, contaminated land, or river basin management. A landslide of contaminated soil into surface water implies an instantaneous exposure of the water to the soil, dramatically changing the prerequisites for the mobilisation and transport of pollutants. In this study, an analytical approach is taken to simulate the transport of suspended matter released in connection with landslides into rivers. Different analytical solutions to the advection-dispersion equation (ADE) were tested against the measured data from the shallow rotational, retrogressive landslide in clayey sediments that took place in 1993 on the Göta River, SW Sweden. The landslide encompassed three distinct events, namely an initial submerged slide, followed by a main slide, and a retrogressive slide. These slides generated three distinct and non-Gaussian peaks in the online turbidity recordings at the freshwater intake downstream the slide area. To our knowledge, this registration of the impact on a river of the sediment release from a landslide is one of few of its kind in the world and unique for Sweden. Considering the low frequency of such events, the data from this landslide are highly useful for evaluating how appropriate the $\mathrm{ADE}$ is to describe the effects of landslides into surface water. The results yielded realistic predictions of the measured variation in suspended particle matter (SPM) concentration, after proper calibration. For the three individual slides it was estimated that a total of about $0.6 \%$ of the total landslide mass went into suspension and was transported downstream. This release corresponds to about 1 to $2 \%$ of the annual suspended sediment transport for that river stretch. The studied
\end{abstract}

landslide partly involved an industrial area, and by applying the analytical solution to estimate the transport of metals in the sediments, it was found that landslides may release a significant amount of pollutants if large contaminated areas are involved. However, further studies are needed to develop more detailed descriptions of the transport processes. There is also a need to increase the knowledge on possible environmental consequences in the near and far field, in a short- and long-time perspective. In summary, the release of pollutants should not be neglected in landslide risk assessments.

\section{Introduction}

\subsection{Mass movement}

Mass movement of contaminated soil into surface water encompasses both physical and chemical processes and is an interdisciplinary research area. The stability of a slope (e.g. hillside or riverbank) is governed by the balance between resisting and driving forces. When the driving forces exceed the resisting forces by cohesion and friction between soil particles, the soil starts to move (Lambe and Whitman, 1979). As the contact between particles diminishes, and as the moving soil mass becomes liquefied (a slurry), particles come into suspension and are no longer attached to each other. The effective stresses between particles are reduced and the forces act through the fluid instead (TerStepanian, 2000). As the soil mass moves into a surface water (a river, lake, or coastal area), it causes instantaneous hydraulic changes and generates surface gravity waves through 
the impulse induced by the soil mass impacting the water (Heller, 2008).

Mass movement causes physical disturbance, redistribution of sediments, and an increase in suspended particle matter (SPM), which affects both the physical environment and the ecology. Anthropogenic substances that accumulate in sediments are nutrients, heavy metals, and organic pollutants. The pollutants may occur dissolved, free or in complexes, or associated with the particulates either adsorbed or precipitated. From a risk perspective, the possible shifts between different states and species have large implications. Such shifts towards dissolved species imply significant impact due to their higher bioavailability (Goossens and Zwolsman, 1996).

\subsection{Impact on water quality}

Only a few studies have been reported on the effects on water quality from the mass movement. Some investigations have discussed the pollution of rivers and lakes from peat or bog flows and from bank erosion during flooding (Caruso, 2001). In a study by McCahon et al. (1987), an effort was made to back-calculate the impact on water quality from a peat slide that caused fish kill. It was demonstrated that the slide induced considerable change in water chemistry with large increases in the concentration of suspended solids and metals. The active and slow-moving landslide in the headwaters of Sumas River, near the US-Canada border, releases up to $90000 \mathrm{~m}^{3}$ of excess sediment each year, which is carried downstream by Swift Creek (USEPA, 2011). These sediments in the river contain naturally occurring asbestos (thin fibres from silicate minerals), caused by running water from the Sumas Mountain that picks up asbestos-containing rocks and soil in the landslide and carries them downstream. With respect to sediment transport, the landslide that occurred in 1990 in the Surma Khola Valley, the high mountain region of the central Nepalese Himalaya, increased the suspended sediment concentration in the Surma Khola River by approximately 50 times for a short period of time (Reis, 2000). It took about three days for the sediment pulse to pass one of their gauging stations; however, the discharge decreased much more slowly. During that time the calculated suspended sediment transport increased by three orders of magnitude, from $62 \mathrm{~g} \mathrm{~s}^{-1}$ to $23 \mathrm{~kg} \mathrm{~s}^{-1}$, and it was calculated that the specific suspension delivery during these days reached twice the annual delivery (Reis, 2000). In a thesis by Rhoades (2008), mercury contamination from bank erosion was estimated for the South River, Virginia, USA. Leakage of mercury from industrial activities in the past had contaminated riverbank sediments. The concentration ranged from 5 to $140 \mathrm{ppm}$, and contaminated sediments were delivered to the river channel through bank erosion. It was estimated that a minimum of $161000 \mathrm{~m}^{3}$ of sediment eroded from the bank each year, releasing about $110 \mathrm{~kg}$ of $\mathrm{Hg}$ per year (Rhoades, 2008).
A study on Swedish mass movement events, mainly rotational and translational earth slides, earth falls, and debris falls, revealed that out of 42 studied events, contaminant mobilisation could be suspected in 15 of these events (Åkesson, 2010). In the same study, hydrodynamic observations were made and it was found that surging (17 of these events), damming effects (29 events), and a vast increase in suspended matter (14 events) were common consequences. One of the documented slides is the Yara earth slide in 2007, which occurred within an industrial area (earlier producing and today distributing mineral fertilizers). The slide transported about $1200 \mathrm{~m}^{2}$ of landfill material and partially contaminated clays into Ståthöga bay near the city of Norrköping, SE Sweden. As a result, a new bay was formed at the site of failure, exposing contaminated mass estimated to contain hundreds of kilos of arsenic, lead, zinc, and copper to the neighbouring surface waters. Other relevant landslides in Sweden are the Tångböle and Göta slides. The Tångböle slide took place in 1995 adjacent to the Indal River, Sweden, and caused an instantaneous and more than six-fold increase in sedimentation in the nearby lake Gevsjön. Signs of pollution were noted and local supply and usage of freshwater were restricted. The 1957 Göta earth slide in Göta River, SW Sweden, displaced 300000 to $450000 \mathrm{~m}^{2}$ of land and involved a pulp mill factory. In this accident three men died and several more were injured. The material damage was extensive and large amounts of plausibly contaminated scree lay uncovered and exposed to both wind and water.

There are several recent studies on the sediment delivery from landslides, their contribution to the sediment flux, and erosion of the displaced toe (see for example Mackey and Roering, 2011; Schwab et al., 2008; Bayer and Linneman, 2011; Ono et al., 2011). In general, sediment discharge can be divided into stream channel sediment transport (bed load, suspended load, and wash load) and land surface transport (mass movement) (Mouri et al., 2011). These two transport pathways are associated with different time scales, where the transport on a sloping land surface during a landslide is rapid compared to that in a stream channel. Mouri et al. (2011) modelled such a system by combining a slope model with a stream channel model. The study by Göransson et al. (2009) divided the sediment transport from a landslide containing contaminated soil into an instantaneous release of sediment followed by a long-term release and presented a description of the processes involved (Fig. 1).

\subsection{Mathematical modelling of suspended sediment transport}

The advection-dispersion equation (ADE) for the modelling of transport and spatial distribution of suspended matter in rivers is a natural starting point. For a river, some distance away from the release point, the suspended sediment is assumed to be fully mixed and the concentration uniform over any cross section. Spatially, the concentration only varies 


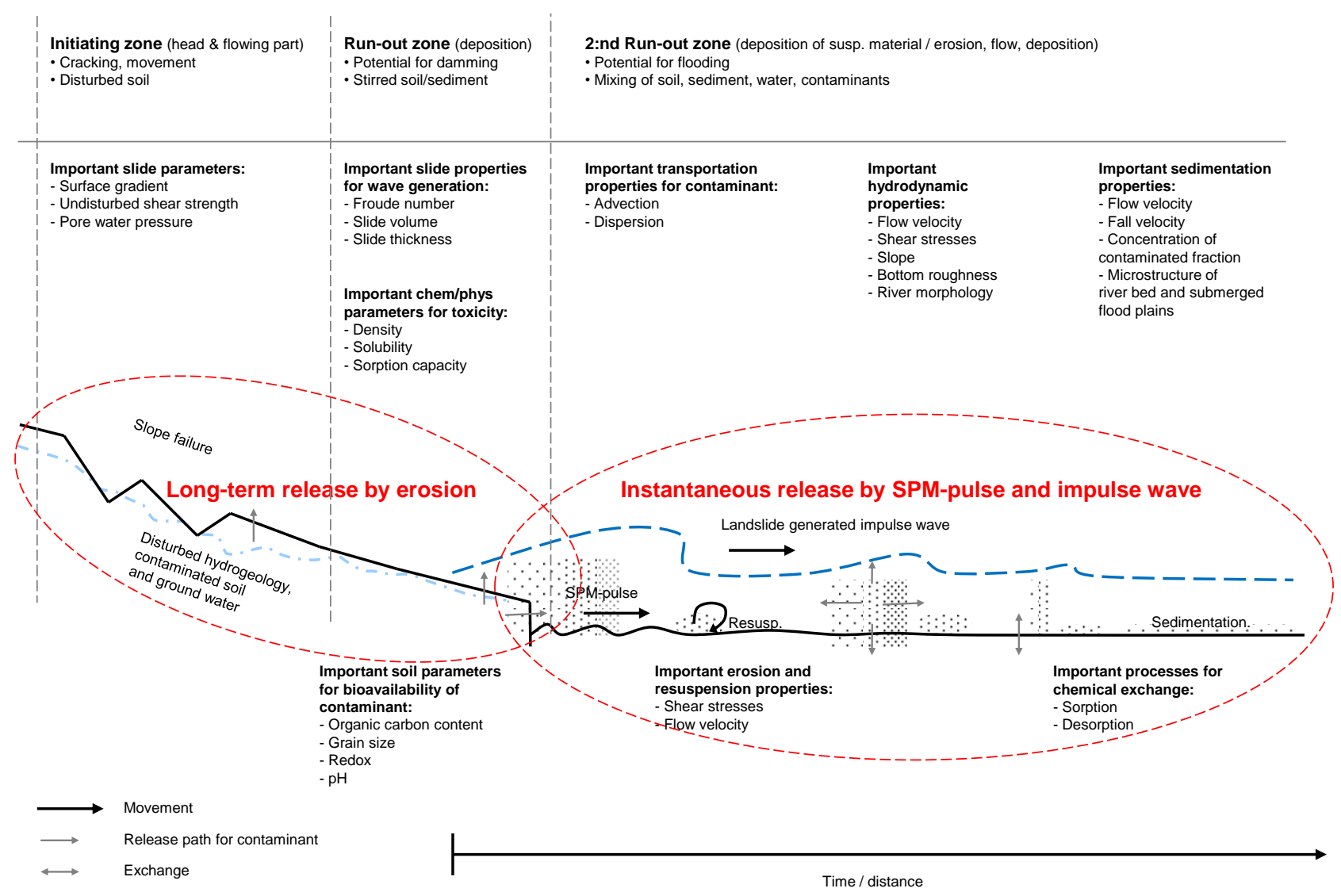

Fig. 1. Schematic description of the release of contaminants into surface water from a landslide (further developed from Göransson et al., 2009). In landslide nomenclature, the zone where a mass movement is initiated is referred to as the "initiating zone", and the zone where deposition takes place is in general referred to as the "run-out zone". The illustration describes how the event can be divided into three zones, depending on processes, and what the governing process parameters are in each zone. After the event, the release and transport of contaminants can be divided into an instantaneous release and a long-term release (dashed ovals).

along the river, and the sediment concentration follows a normal distribution in space, at any given time, which propagates downstream with the mean velocity. The dispersion of the suspended sediment is mathematically described by Fick's law, where the dispersion coefficient includes the combined effects of molecular diffusion, turbulent mixing, and mixing due to transverse and vertical shear associated with crossstream velocity differences (Singh and Beck, 2003).

However, results from field experiments and observations in natural channels have shown that a suspended sediment, colloid, or dissolved element pulse does not always form a normal distribution, but frequently skewed distributions with sharp fronts and long tails occur (Jobson, 2001). This phenomenon is commonly referred to as non-Fickian dispersion and may be a result of one or a combination of the following mechanisms: (i) complete hydrodynamic mixing is not fully reached at the point of observation, (ii) storage by reversible or irreversible exchange with stagnant or slowly moving water masses ("dead zones"), porous streambeds, hyporheic zones, and viscous sublayers, and (iii) biogeochemi- cal reactions, such as sorption, dissolution/precipitation, and decay/production take place.

There are various storage processes that influence the transport of fine particles and hence the spatial distribution of particles, which have been reported in numerous studies (see for example Atkinson and Davis, 2000; Davis et al., 2000; Davis and Atkinson, 2000; Chanson, 2004; Karwan and Saiers, 2009; Singh and Beck, 2003; Deng et al., 2001, 2002; Bender et al., 2011; van Mazijk and Veling, 2005; Deng and Jung, 2009). Nevertheless, the study by Karwan and Saiers (2009) suggests that transient storage can often be neglected and that a model accounting for advection, dispersion, and first-order kinetic deposition only may be sufficient to describe micrometer-sized particles. They also found that the deposition rate increased with a decrease in flow and that the dispersion coefficient had positive correlation with the logarithm of the stream velocity. Huang et al. (2008) worked with transient storage in wetlands and found large differences in advection, dispersion and filtration depending on flow regime and aquatic vegetation composition. 
Karwan and Saiers (2009), Huang et al. (2008) and Paul and Hall (2002) concluded that very fine particles can travel long distances under high flows. Paul and Hall (2002) also found that fine particle transport distances increased with stream size and suggested that the particle transport distance primarily can be determined by stream velocity and depth, since they found no relationship between transient storage and depositional velocity.

The ADE for suspended sediment transport generally uses deposition as the sink term (Karwan and Saiers, 2009; Huang et al., 2008). Thomas et al. (2001) found clear influence of fall velocity on deposition velocity for particulate organic matter and suggested that gravitational forces control the deposition for particles $>100 \mu \mathrm{m}$. Hamm et al. (2011) studied silt-sized particles in an open channel flow with permeable beds. With the method used, no significant variation due to particle size in the effective deposition velocity relative to still water was found, but there was a relationship between deposition rate and bed shear stress.

\subsection{Objectives and procedure}

The objectives of this study are threefold:

1. To identify the main mechanisms determining the evolution of the suspended sediment concentration after a landslide into surface water based on field observations from Göta River, SW Sweden.

2. To model the evolution of the suspended sediment concentration using analytical solutions to the advectiondispersion equation and assess the usefulness of such solutions.

3. To estimate the contribution of the suspended sediment transport from the landslide to the sediment budget and pollution load from Göta River.

The assumption is made that the ADE in one dimension (1D) for a slug injection, coupled with appropriate source/sink terms under given initial and boundary conditions, is appropriate to describe the initial transport of suspended sediment released through the landslide. The mass movement into the river is assumed to be a very fast process compared to the retention time of the river, implying instantaneous and uniform mixing across the river.

A landslide occurred along the Göta River in 1993 in the municipality of Agnesberg, located just north of Gothenburg city, Sweden. Detailed turbidity measurements were carried out at a freshwater intake about $2.6 \mathrm{~km}$ downstream the landslide area. These data were used to evaluate the ADE for describing the transport of suspended sediment. The landslide was a rather small slide, mainly consisting of clay that is highly sensitive to disturbances, partly involving an industrial site. The observed turbidity time series, which was converted into suspended sediment concentrations based on a calibration relationship derived using field samples, is unique in its kind, and no other registration of the variation in suspended sediment concentration due to a landslide is known to the authors. The recorded pulses show a skewed, nonGaussian form in time, with a steep and quick rising limb followed by a slower falling limb and a long tail.

\section{Study area}

\subsection{Göta River}

The Göta River stretches from Lake Vänern to the outlet at the city of Gothenburg (Fig. 2a-b). The mean flow is about $565 \mathrm{~m}^{3} \mathrm{~s}^{-1}$. South of Kungälv, the river divides into two branches around a large island; the northern branch (i.e. the Nordre River) receives on the average $2 / 3$ of the total discharge, whereas the remaining discharge goes through the southern branch (still referred to as Göta River) (GÄ̈VVF, 2006). The river flow is regulated by three hydropower stations located upstream the branching. The river stretch is quite straight with only a few meanders and has a mean width of 200-300 m before the branching and of $100 \mathrm{~m}$ in the southern branch. The main channel has typical depths of $7-10 \mathrm{~m}$ with deeper local cavities. The channel margin forms in most cases a distinct bank shelf. River sediments consist mainly of thick layers of glacial and post-glacial cohesive sediments with thin layers of silt and sand. The areas surrounding the river are pasture lands, forests, bedrock, and small urban industrial areas. Almost no sedimentation occurs in the river, and the transport of inorganic suspended particles has been estimated to about $130000 \mathrm{t} \mathrm{yr}^{-1}$, of which $50000 \mathrm{tyr}^{-1}$ are transported through the southern branch (Sundborg and Norrman, 1963). Göransson et al. (2011) estimated the annual suspended sediment transport in the southern branch to about $30000 \mathrm{t}$. By adding the organic fraction, the total load of suspended matter increases up to $25 \%$.

\subsection{Landslides}

The areas along Göta River have the largest landslide frequencies in Sweden. Most of the slides have been classified as rotational earth slides, and due to the occurrence of so-called quick clay, some slides have propagated to encompass huge areas. Along the $93 \mathrm{~km}$ stretch from Lake Vänern and through the southern branch of the river, more than 60 slides have been documented over time, the first one in a church book from mid 1150, and at least 16 of these slides involved large areas (up to $\sim 500$ ha). Partial or full damming of the river, landslide-generated waves and an increase in water turbidity are some documented effects in connection with landslides. The most recent events involved a municipality (Surte landslide, 1950), a pulp mill factory (Göta landslide, 1957) and an industrial site (Agnesberg landslide, 1993). The risk for the spreading of pollution from contaminated soil was only mentioned in a few of the landslides, but no measurements were ever carried out to analyse possible 

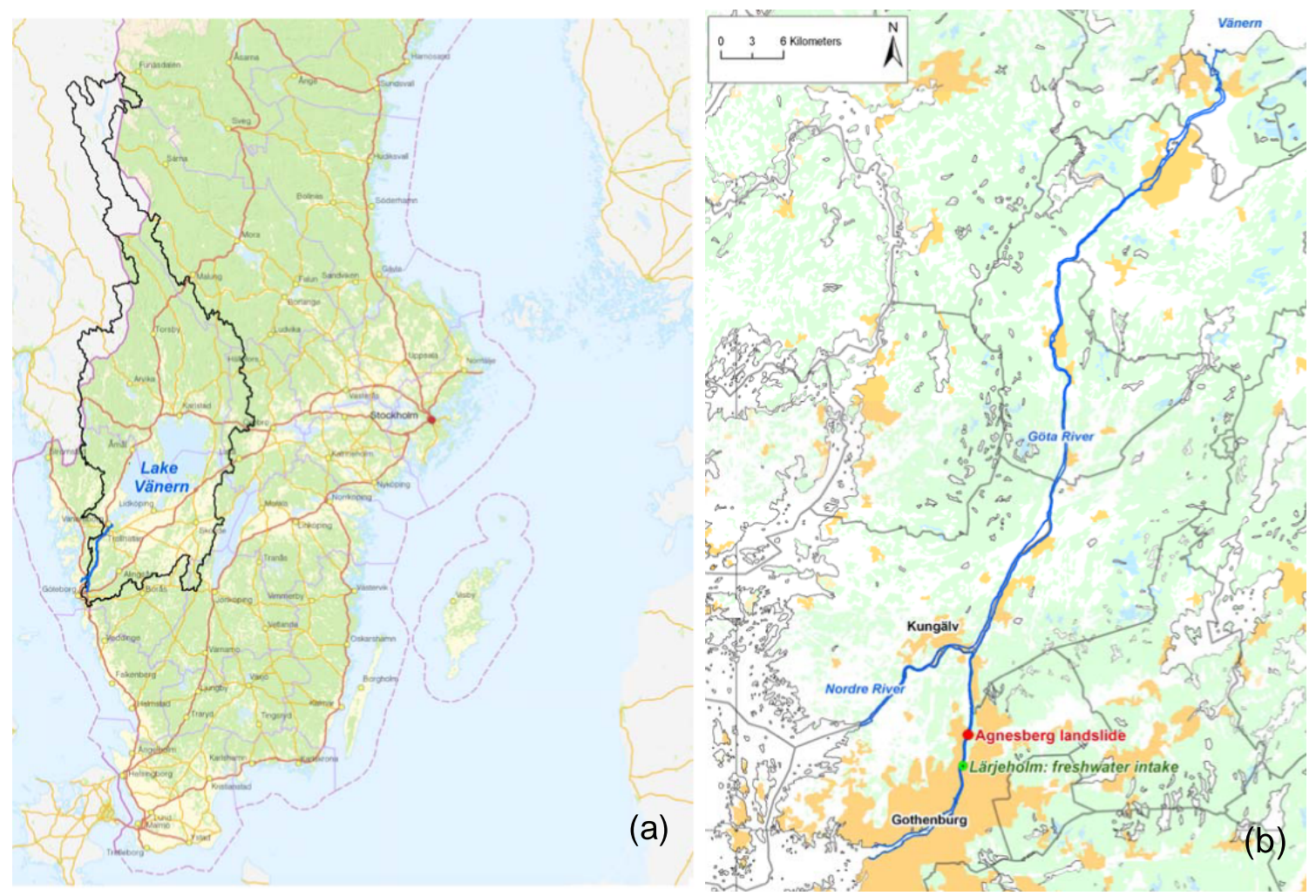

Fig. 2. (a) The Göta River and Lake Vänern catchment. (b) The Göta River and the study area showing the locations of the Agnesberg landslide and the freshwater intake. Background maps: Lantmäteriet ${ }^{\circledR}$.

environmental consequences. There are several industrial areas adjacent to the river where a significant risk for landslides exists (Göransson et al., 2009).

\subsection{Water quality}

Several stretches of the Göta River, some tributaries to the river, and the estuary of Nordre River, are protected under the European Natura 2000 network (centrepiece of EU Nature \& Biodiversity Policy). The river serves as an important waterway to and from harbours along the river and around Lake Vänern. The river is both the recipient of treated wastewater and the drinking water supply for 700000 inhabitants in Gothenburg city. The water quality in the river is primarily affected by direct runoff from urban, rural, and livestock areas, treated wastewater from urban areas, combined sewer overflow during heavy rainfall (Åström et al., 2007), leakage from contaminated sites, and accidental spills from industries and vessels. The water quality is to a large extent influenced by the outflow from Lake Vänern into the river (GÄVVF, 2006). Today, nutrients and microorganisms from the wastewater treatment plant are assumed to be the main threat to health and environment. Turbidity (as well as $\mathrm{pH}$, redox, and conductivity) is continuously recorded at seven gauging stations along the river, with the purpose of providing an early warning in case of reduced water quality. The most downstream gauging station is located at the freshwater intake (Lärjeholm; see Fig. 2). In general, the intake is closed about 100 days a year, during which freshwater is taken from a system of reservoirs. If the water quality deviates from normal conditions, additional sampling will start automatically. However, as a direct consequence of the combined risk of landslide and contamination (see further Göransson et al., 2009), large investments are made on remediation and reinforcement of prioritised contaminated sites adjacent to the river.

\section{Model of concentration variation in a river due to sediment release from landslides}

\subsection{Advection-dispersion equation (ADE)}

Traditionally, the ADE (see Fisher et al., 1979) has been used to model the concentration in rivers and how it evolves in time and space due to a pollution release. In a river, a reasonable simplification is to employ a one-dimensional approach in space, assuming that all quantities in the ADE can be adequately represented by their cross-sectional averages. Such averaging implies that the dispersion coefficient, which characterizes the longitudinal mixing, not only includes the diffusive processes but the effects of the cross-sectional variation 
in velocity as well. As a first approximation, the ADE will be used in the present study to describe the effects of a landslide on the concentration of suspended material in a river. It will be assumed that most of the material released into the river during a landslide will be transported in suspension, and coarser material that may move as bed load is not taken into account. Karwan and Saiers (2009) employed a similar equation to model particle movement in a stream, where the deposition was quantified through a coefficient corresponding to $w / h$ (settling velocity over water depth). Furthermore, a second equation was used to describe the transient storage (compare Atkinson and Davis, 2000).

The one-dimensional ADE with a sink term (sediment deposition) for the suspended sediment transport in a river may be written

$$
\frac{\partial c}{\partial t}+U \frac{\partial c}{\partial x}=D \frac{\partial^{2} c}{\partial x^{2}}-\frac{w c}{h}
$$

where $c$ is the concentration (mass per unit volume), $U$ the mean velocity in the river, $D$ the dispersion coefficient, $w$ the settling velocity, $h$ the water depth, $x$ the spatial coordinate along the river, and $t$ the time. The equation describes how sediment is transported downstream with the mean velocity (advection), at the same time being subject to mixing (dispersion) and settling at the bottom. The settling is quantified by the last term on the right-hand side of Eq. (1), which acts as a sink for the sediment. No attempt is made to describe the mobilization of sediment (pick-up) from the bed, but it will be assumed that the sediment transported by the river is supplied from the landslide only, through an instantaneous pulse (mathematically described through a Dirac delta function) at some specific location.

The ADE may be solved analytically for a wide range of problems where the initial, boundary, and forcing conditions are sufficiently simple. However, for applications to a more complex situation, which is typically the case in practical studies in natural rivers, the ADE must be solved numerically, for which many different techniques are available (Vreugdenhil and Koren, 1993). In the present study, however, an analytical approach will be taken to investigate whether the ADE can reproduce the observed variation in SPM concentration in a river as a result of a landslide. If an analytical solution to the ADE can capture the main features of the variation in SPM, then certain characteristic quantities such as the maximum concentration, time to peak, and duration of the event may be predicted in the case of a landslide occurring upstream a certain location. Furthermore, analytical solutions to the ADE may be efficient to use for general risk assessment when a large number of alternatives and their potential impacts need to be determined.

\subsection{Analytical solution to the ADE}

The solution to Eq. (1) for the case of a release of the sediment mass $M(\mathrm{~kg})$ instantaneously at $x=0$ and $t=0$ is given by (Carslaw and Jaeger, 1959)

$c(x, t)=\frac{M}{A \sqrt{4 \pi D t}} \exp \left(-\frac{(x-U t)^{2}}{4 D t}-\frac{w t}{h}\right)$

where $A$ is the cross-sectional area of the river. This equation represents a concentration distribution that follows a Gaussian shape in space at any given time, where the centreline of the distribution moves downstream with the velocity $U$ (if $U>0$, otherwise the distribution moves upstream). Simultaneously with this advection, the distribution is spreading symmetrically around the maximum value because of dispersion. If $w=0$, the Gaussian shape contains the same mass of material at all times $(=M)$, but if $w>0$ then the mass in the water is decreasing. The solution given by Eq. (2) assumes that the river and sediment properties (i.e. $A, D, U$, $h$, and $w$ ) are constants, not changing with space or time. Analytical solutions to ADE for other initial and boundary conditions may be found in Carslaw and Jaeger (1959) and Crank (1975).

In general, with due regard to the boundary and initial conditions, it is possible to derive new solutions simply by superimposing existing solutions, since the governing differential equation (Eq. 1) is linear for constant coefficients. Thus, if a landslide contains two main fractions of material with different settling velocities, the transport of these fractions could be modelled separately with Eq. (2) and the solutions are then added together to obtain the total concentration of SPM, if there is negligible interaction between the two fractions when they are transported. Also, a more complex release of material from a landslide, taking into account the time history of how the material was released to the river and not regarding it as an instantaneous source, may be described through the superposition of a large number of instantaneous sources of proper magnitude and location in time.

Rewriting Eq. (2) in terms of a constant mass transport rate $m$ (unit $\mathrm{kg} \mathrm{s}^{-1}$ ) at time $t_{\mathrm{s}}$ during a short period $\Delta t$ yields the following solution,

$$
\begin{aligned}
& c(x, t)=\frac{m \Delta t}{A \sqrt{4 \pi D\left(t-t_{s}\right)}} \\
& \quad \exp \left(-\frac{\left(x-U\left(t-t_{\mathrm{s}}\right)\right)^{2}}{4 D\left(t-t_{\mathrm{s}}\right)}-\frac{w\left(t-t_{\mathrm{s}}\right)}{h}\right)
\end{aligned}
$$

valid for $t>t_{\mathrm{s}}$. Thus, a landslide event, assumed to be made up of a large number of such short events, where the sum of all small releases $m$ will yield $M$, produces the following solution (Larson et al., 1987):

$$
\begin{aligned}
& c(x, t)=\frac{1}{A \sqrt{4 \pi D}} \int_{0}^{t} \\
& m\left(t^{\prime}\right) \frac{\exp \left(-\frac{\left(x-U\left(t-t^{\prime}\right)\right)^{2}}{4 D\left(t-t^{\prime}\right)}-\frac{w\left(t-t^{\prime}\right)}{h}\right)}{\sqrt{t-t^{\prime}}} \mathrm{d} t^{\prime}
\end{aligned}
$$


where $m\left(t^{\prime}\right)$ is a function describing the time history of material release from the landslide and $t^{\prime}$ is a dummy integration variable. A possible ad-hoc description of how the material release occurs during a landslide, including the initial mixing over the river cross section, is given by an exponential decay function,

$m=m_{\mathrm{o}} e^{-\alpha t}$

where $m_{\mathrm{o}}$ is the initial rate of material release and $\alpha$ is a parameter quantifying how rapidly the release rate goes to zero. Equation (5) characterizes the expected properties of a landslide with regard to the material release: initially the release rate should be large, but over the time scale of the slide, this rate should decay towards zero.

Substituting Eq. (5) into Eq. (4) yields after some calculation

$$
\begin{gathered}
c(x, t)=\frac{m_{\mathrm{o}}}{A \sqrt{\pi D}} \exp \left(-\alpha t+\frac{x U}{2 D}\right) \int_{0}^{\sqrt{t}} \\
\exp \left(-\left(\frac{C_{1}}{t^{\prime 2}}+C_{2} t^{\prime 2}\right)\right) \mathrm{d} t^{\prime}
\end{gathered}
$$

where the coefficients $C_{1}$ and $C_{2}$ are defined as:

$$
\begin{aligned}
& C_{1}=\frac{x^{2}}{4 D} \\
& C_{2}=\frac{U^{2}}{4 D}+\frac{w}{h}-\alpha
\end{aligned}
$$

The integral in Eq. (6) may be developed in terms of elementary functions, where the solution depends on the coefficient $C_{2}$. If $C_{2}>0$, then the solution contains a sum of real-valued error functions; however, for $C_{2}<0$, the solution will include complex-valued error functions (Abramowitz and Stegun, 1965). Due to limited space, the solutions involving the development of the integral will not be given here.

\subsection{Characteristic quantities for concentration}

Analytical solutions make it possible to identify the governing parameters of the problem at hand, as well as to develop non-dimensional quantities that can characterize the main features of the solutions. Such quantities can also be useful in fast and simple predictions as a basis for decisionmaking in connection with a pollution release. In the following, some non-dimensional quantities will be developed based on Eq. (2), which can be potentially useful for the initial assessment of the impact from a landslide event.

At a specific location away from the point where the mass of sediment is released (e.g. slide area), the concentration variation in time is in general not symmetrical (compare frozen cloud assumption), and the specific time when the maximum concentration is recorded at a location $x_{0}$ depends on the values of the three parameters $U, D$, and $w$. Solving

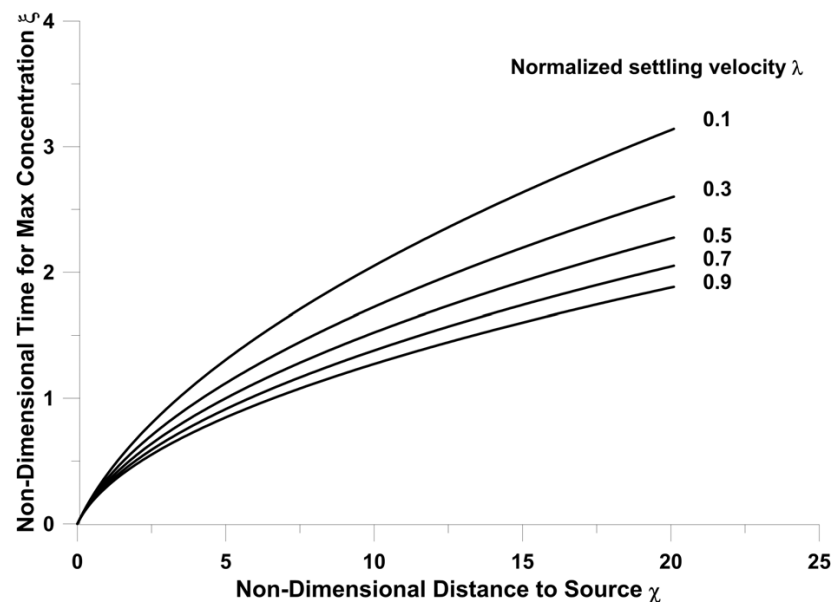

Fig. 3. Non-dimensional time for the occurrence of maximum concentration at a particular location away from a pollution release as a function of non-dimensional distance and fall speed.

for when $\partial c / \partial t=0$ at $x_{\mathrm{o}}$ (Eq. 2) yields the following equation for the time $t_{\max }$ when the maximum concentration is observed,

$\frac{t_{\max } U^{2}}{D}=\frac{1}{1+4 \frac{w D}{U^{2} h}}\left(\sqrt{1+\frac{x_{\mathrm{o}}^{2} U^{2}}{D^{2}}\left(1+4 \frac{w D}{U^{2} h}\right)}-1\right)$

where the following non-dimensional quantities may be introduced,

$\xi=\frac{t_{\max } U^{2}}{D} ; \quad \lambda=\frac{w D}{U^{2} h} ; \quad \chi=\frac{x_{\mathrm{o}}^{2} U^{2}}{D^{2}}$

making it possible to express Eq. (8) as:

$\xi=\frac{1}{1+4 \lambda}(\sqrt{1+\chi(1+4 \lambda)}-1)$.

Equation (8) illustrates the complex relationship between $t_{\max }$ and $U, D$, and $w$. For constant $U$ and $D, t_{\max }$ decreases with increasing $w$, whereas for both increasing values on $U$ and $D, t_{\max }$ tends to decrease (all other parameters kept constant for a specific variation). Figure 3 plots $\xi$ as a function of $\chi$ for various values on $\lambda$ based on Eq. (10) for easy evaluation of $t_{\max }$ in terms of the governing parameters.

Using Eq. (2) with $t=t_{\max }$, where $t_{\max }$ is obtained from Eq. (8), gives the maximum concentration at $x=x_{0}$. The non-dimensional expression for the maximum concentration is

$\sigma(\lambda, \chi)=\frac{1}{\sqrt{4 \pi \xi}} \exp \left(-\frac{(\sqrt{\chi}-\xi)^{2}}{4 \xi}-\lambda \xi\right)$

where $\xi$ is given by Eq. (10) and

$\sigma=\frac{c_{\max } A D}{M U}$. 
Figure 4 shows $\sigma$ as a function of $\chi$ for various values on $\lambda$ based on Eq. (11). The information provided by Eqs. (10) and (11) may be useful for quick predictions of the effects (i.e. $t_{\max }$ and $c_{\max }$ at a certain location) of a sediment release in connection with a landslide.

It may be interesting to look at the asymptotic properties of Eq. (8) for various limits to the governing parameters $U$ and $D$. If $D \rightarrow 0$, then $t_{\max }$ will approach $x_{\mathrm{o}} / U$, that is, the maximum will occur at a time given by the advection speed only (satisfying the frozen cloud approximation). On the other hand, if $U \rightarrow 0$, then

$t_{\max }=\frac{h}{4 w}\left(\sqrt{1+4 \frac{x_{\mathrm{o}}^{2} w}{h D}}-1\right)$

which for the case of $w \rightarrow 0$ implies $t_{\max }=x_{\mathrm{o}}^{2} / 2 D$.

\section{Comparison with data}

\subsection{Agnesberg landslide}

The Agnesberg landslide occurred on 14 April 1993. It took place within an industrial site located on the eastern bank of the southern branch of the Göta River, some $10 \mathrm{~km}$ upstream central Gothenburg and about $2.6 \mathrm{~km}$ upstream the freshwater intake at Lärjeholm (Fig. 2). In total, the slide involved approximately $8000 \mathrm{~m}^{2}$, of which $2400 \mathrm{~m}^{2}$ correspond to the affected ground surface (Larsson et al., 1994). The river was partially dammed since a portion of the cross section was covered in a $2-\mathrm{m}$ thick layer of clay. The site of failure was located within and along a stretch of the river characterised by thick (about $33 \mathrm{~m}$ deep) deposits of compressible and sensitive clay resting upon extensive deposits of sand with interbedded silt and clay layers (Larsson et al., 1994). Quick-clay was known to be present, and geotechnical studies later detected substantial artesian groundwater pressures within the sand layers. Topographically, the land area can best be described as somewhat superficially flat with the uppermost soil layer composed of filling material, resting above clay containing plant and shale remnants with some contribution of mud. The bottom profile at the site of the event was reconstructed based on adjacent sounding and geotechnical investigations. The bank shelf probably formed a 24-m wide shallow section with a water depth slowly increasing from $1 \mathrm{~m}$ closest to the bank to about $2 \mathrm{~m}$ at the deep end. The bank ended with a steep subaqueous slope with an estimated height of $6 \mathrm{~m}$ and a slope angle of about 1:1.5 (Larsson et al., 1994).

The landslide involved three distinct slides (events). The first slide represented the initiating slope failure of the subaqueous slope, mainly composed of fine sediments with a dominance of clay. The second (main slide) and third slide (retrogressive slide), on the other hand, involved land areas where the top layer is composed of filling material upon dry

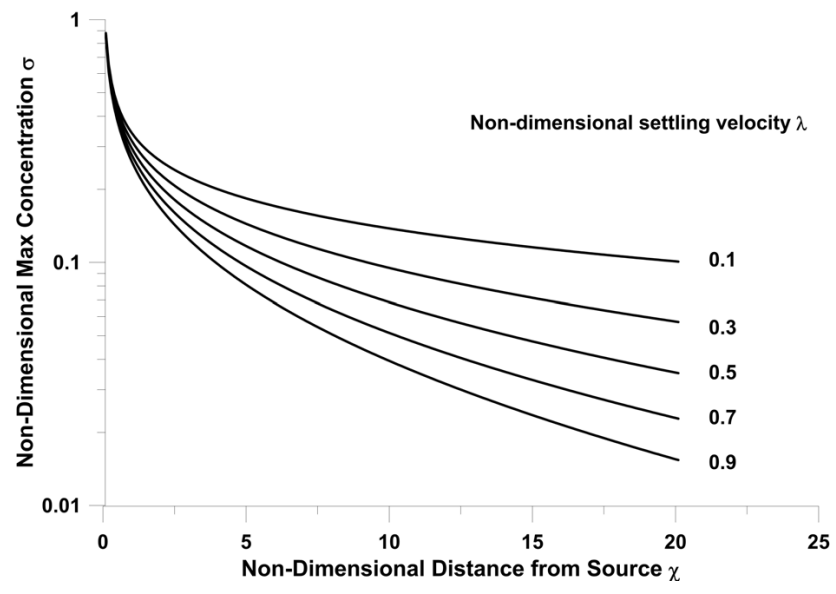

Fig. 4. Non-dimensional maximum concentration at a particular location away from a pollution release as a function of nondimensional distance and fall speed.

crust clay (possibly with contribution of fluvial sediments). The landslide was classified as a rotational slide around a circular failure plane. Figure 5 illustrates estimated pre- and post-slide bottom profiles, probable failure planes, and the course of events.

Since no real-time observations were made at the slide location, the course of the slide events was subsequently developed based largely on recordings of turbidity made continuously at the Lärjeholm freshwater intake (mean values provided every minute). Three major sediment pulses were registered at Lärjeholm, reflecting the three successive slide events (Fig. 6). The first pulse was timed at approximately 6 a.m., whereby the level of turbidity increased from 3 to 10FTU (Formazin Turbidity Units). The second pulse occurred roughly three hours later, demonstrating an even greater increase in turbidity going from 4 to $12 \mathrm{FTU}$. The third and last pulse was dated to about 12.30 p.m., $6 \mathrm{~h}$ after the initial event, during which the level of turbidity increased from 7 to 9 FTU. Of the three events, only the two latter were witnessed by people. River flow was not measured at the site of the event, but from recordings at Lilla Edet, about $42 \mathrm{~km}$ upstream, the flow was estimated to be $180 \mathrm{~m}^{3} \mathrm{~s}^{-1}$, which is slightly above the mean flow. Pre-landslide geotechnical data were available for adjacent areas, and based on ensuing studies, it was concluded that the movement started as a subaqueous slide along the underwater slope, in turn triggering and successively causing the main (second) and the third (last) slide event some three and six hours later, respectively (Larsson et al., 1994). Passing ships may also have influenced the course of events, potentially imposing transient stresses along the already sensitive reach. Dredging was later undertaken in order to restore the channel morphology. However, due to major concerns about further movements, stabilisation measures were first completed both on land and along the channel bed (Larsson et al., 1994). 


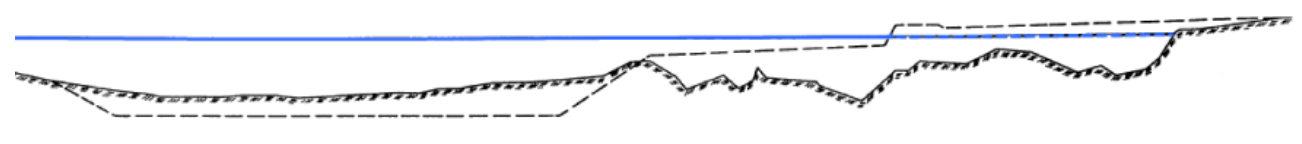

(a)
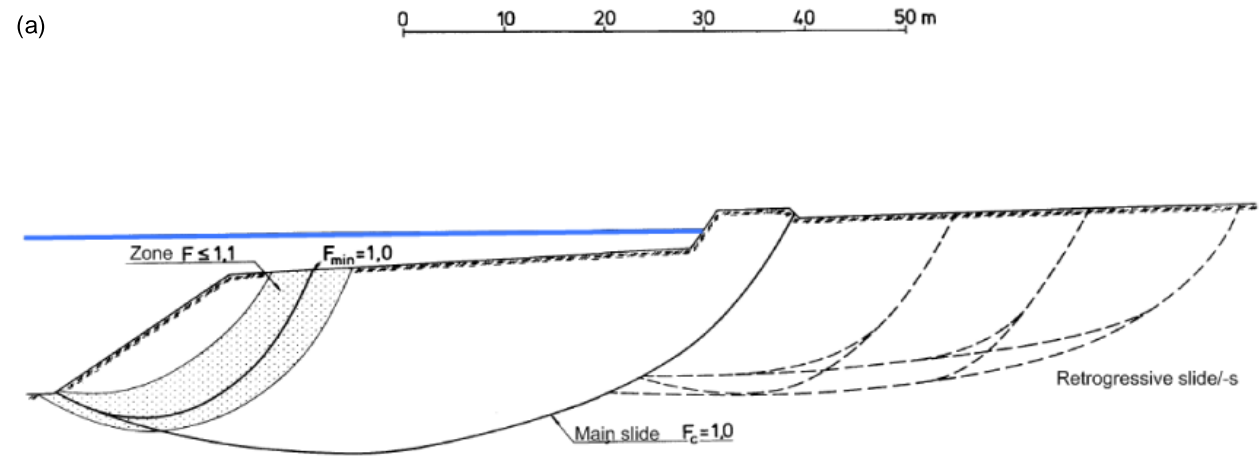

(b)

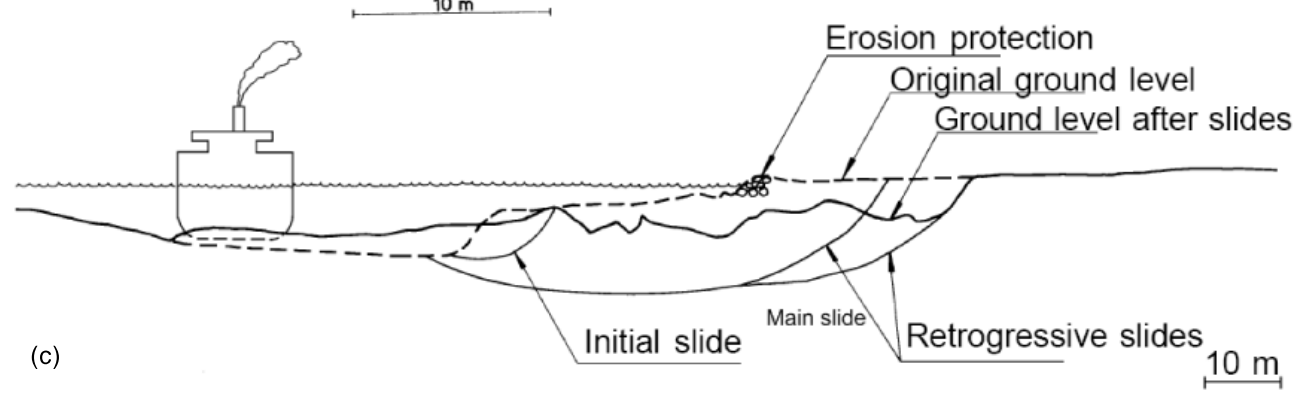

Fig. 5. (a) Estimated pre-slide (dashed line) and surveyed post-slide (cross-hatched line) transect of the affected reach of the river, and approximated water level (blue solid line), (b) calculated failure planes $\left(F=\right.$ factor of safety, $F_{\min }=$ minimum stability factor, and $F_{\mathrm{c}}=F$ with respect to cohesion), and (c) probable course of event. Adopted from Larsson et al. (1994).

Immediately after the slide, surface water samples were taken and analysed for selected physical parameters, such as nutrients, pathogens, mercury, and some chlorinated hydrocarbons. The result only showed a slight increase in chlorinated hydrocarbons, but according to the water supply plant, this was surmised not to be a consequence of the slide. However, the samples were not taken in conjunction with the turbidity peaks but later, implying that any notable increase should be associated with erosion from run-out deposits and not with the landslide-generated suspended sediment pulses. Six sediment samples were taken from the run-out deposits 20 days after the event. The samples were analysed for selected metals, PCB (polychlorinated biphenyls), EOX (extractable halo-organic compounds), and PAH (polyaromatic hydrocarbons). The result showed low levels of contamination with average concentrations: $<0.05 \mathrm{mg} \mathrm{Hg} \mathrm{kg}^{-1}$ dry mass; $0.18 \mathrm{mg} \mathrm{Cd} \mathrm{kg}^{-1}$ dry mass; $13.6 \mathrm{mg} \mathrm{Pb} \mathrm{kg}^{-1}$ dry mass; $11.8 \mathrm{mg} \mathrm{Cu} \mathrm{kg}^{-1}$ dry mass; $16.7 \mathrm{mg} \mathrm{Cr} \mathrm{kg}^{-1}$ dry mass; $10.6 \mathrm{mg} \mathrm{Ni} \mathrm{kg}^{-1}$ dry mass; $64.5 \mathrm{mg} \mathrm{Zn} \mathrm{kg}^{-1}$ dry mass; $<0.05 \mathrm{mg}$ PAH kg$^{-1}$ dry mass; $0.81 \mathrm{mg} \mathrm{EOX} \mathrm{kg}^{-1}$ dry mass (Göteborg Vatten, 2005). The landslide run-out deposit samples had an average content of $82.2 \%$ dry mass and with a loss of ignition of $4.4 \%$ of dry mass (Göteborg Vatten, 2005).

\subsection{Parameter estimation}

The focus in the comparison with the data was on the analytical solution given by Eq. (2). In order to investigate how well this solution can describe the measurements from the $\mathrm{Ag}$ nesberg landslide, a number of quantities (or, parameters) in the solution must be specified. Some of these quantities are known or easily measurable, whereas other quantities may have to be estimated from the data through calibration. The number of quantities used for calibration should be kept to a minimum to provide the greatest confidence in the solution. The following input quantities are required in the analytical solution describing the impact of a landslide:

- Hydrodynamic $(U, A, h$, and $D)$

- Sediment $(w)$

- Landslide $(M)$

The hydrodynamic quantities $(U, A$, and $h)$ could be obtained directly from available measurements using averages over the river stretch of interest, whereas the dispersion coefficient is typically a difficult parameter to assess for a river (often determined from tracer studies). However, there is a 


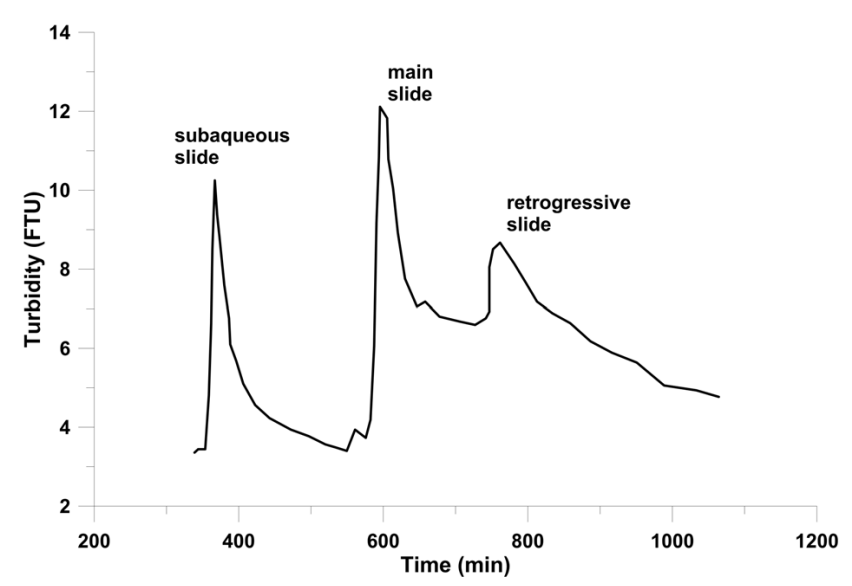

Fig. 6. Measurement of turbidity at Lärjeholm, $2.6 \mathrm{~km}$ downstream the site, at the day of the slide. Adopted from Larsson et al. (1994).

multitude of empirical formulas available for $D$ that will provide approximate values. The sediment properties were determined from river samples, whereas the total mass of sediment released through the landslide was more difficult to estimate (the total volume of the landslide was known, but not the portion of this volume that would contribute to the transport of SPM). Thus, in the end $M$ was determined through calibration. Another unknown quantity that in principal requires calibration is the time of the landslide with regard to the time of measurements at Lärjeholm. Thus, the starting time of the landslide is set to $t=0$ in the analytical solution, but this starting time should be related to the time of measurements to obtain the same reference for the solution and the data. In essence, a starting time $t_{\mathrm{O}}$ should be introduced for the measurements that corresponds to $t=0$ in the model, and this value should be subtracted from the measurement times.

In a first approach, both $M$ and $t_{\mathrm{o}}$ were used in the calibration process simultaneously. The sum of the least-square deviations $\left(S^{2}\right)$ of measured and modelled concentrations was minimized to find optimal parameter values. The minimization was done through a "brute-force" approach where $S^{2}$ was calculated for a large number of combinations of $M$ and $t_{0}$. However, it proved difficult to find a stable global minimum for $S^{2}$, because of the sensitivity to the value of $t_{\mathrm{o}}$. The measured concentration variation with time involved a rapid increase towards the peak value, followed by a slower decrease back to the normal concentration (base level) in the river. Thus, small shifts in time of the concentration distribution may cause large changes in the value of $S^{2}$, although the agreement visually looks satisfactory. Another strategy was then devised to determine optimum parameter values. The emphasis in the calibration was put on $M$, whereas $t_{0}$ was not included, implying that the precise occurrence of the event in time was not described. In order to find the proper value of $M, t_{\max }$ from Eq. (8) was first calculated and then used

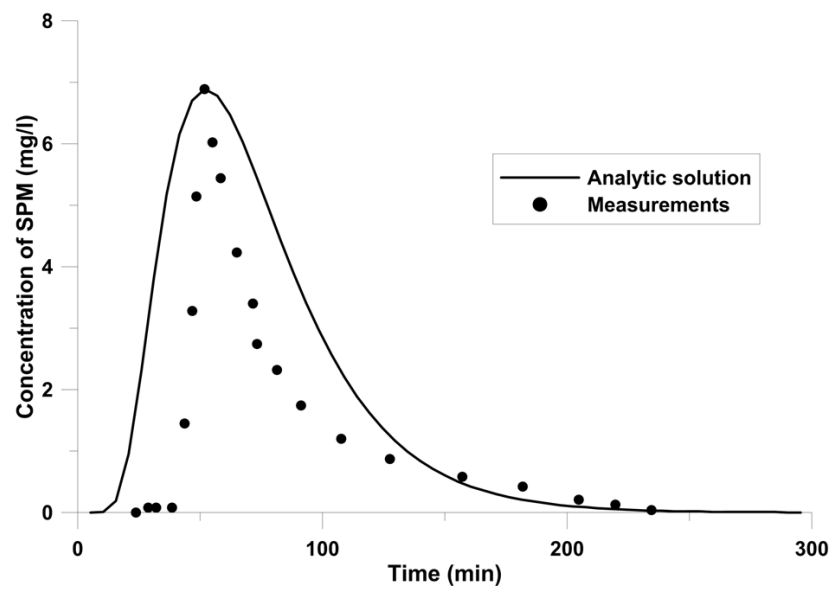

Fig. 7. Calculated and measured variation in SPM concentration with time for the first and initiating event in the Agnesberg landslide, using a dispersion coefficient of $D=230 \mathrm{~m}^{2} \mathrm{~s}^{-1}$.

together with the observed maximum concentration $\left(c_{\max }\right)$ during the landslide event to determine $M$ from Eq. (2). The shape of the calculated concentration distribution was then visually compared with the measured distribution without any consideration of the time of occurrence for $c_{\max }$.

The following values were employed for the river stretch between Agnesberg and Lärjeholm based on detailed measurements of the river morphology and flow at the time: $A=640 \mathrm{~m}^{2}, U=0.3 \mathrm{~m} \mathrm{~s}^{-1}, h=4.1 \mathrm{~m}$, and $x_{0}=2600 \mathrm{~m}$. Analysis indicated that a representative settling velocity for the sediment in the river is $0.002 \mathrm{~m} \mathrm{~s}^{-1}$, although the slide material might have had slightly different properties. The dispersion coefficient was calculated based on the river properties for the actual flow to be $230 \mathrm{~m}^{2} \mathrm{~s}^{-1}$ using the formula proposed by Kashefipour and Falconer (2002), where a Manning's roughness of 0.04 was selected (employing the expression suggested by Deng et al. (2001) gave a value for the diffusion coefficient of $180 \mathrm{~m}^{2} \mathrm{~s}^{-1}$, somewhat lower but still in the same range).

\subsection{Predictions by the analytical solutions}

Figure 7 illustrates the calculated and measured time variation in SPM for the first event in the Agnesberg landslide, where the SPM base level has been subtracted (estimated to $3.4 \mathrm{mg}^{-1}$; a general correlation between turbidity and suspended matter was established for the Göta River based on field measurements). The initial landslide mass $(M)$ was determined to be $170000 \mathrm{~kg}$ from Eq. (2). As discussed in the previous section, no attention was paid to the occurrence in time of the event $\left(t_{\mathrm{o}}\right)$, and the landslide mass was calculated to produce the correct maximum observed concentration $\left(c_{\max }\right)$. When plotting the results, in Fig. 7 and subsequent figures, the measured and calculated concentration distributions have been aligned to yield $c_{\max }$ at the same time. 


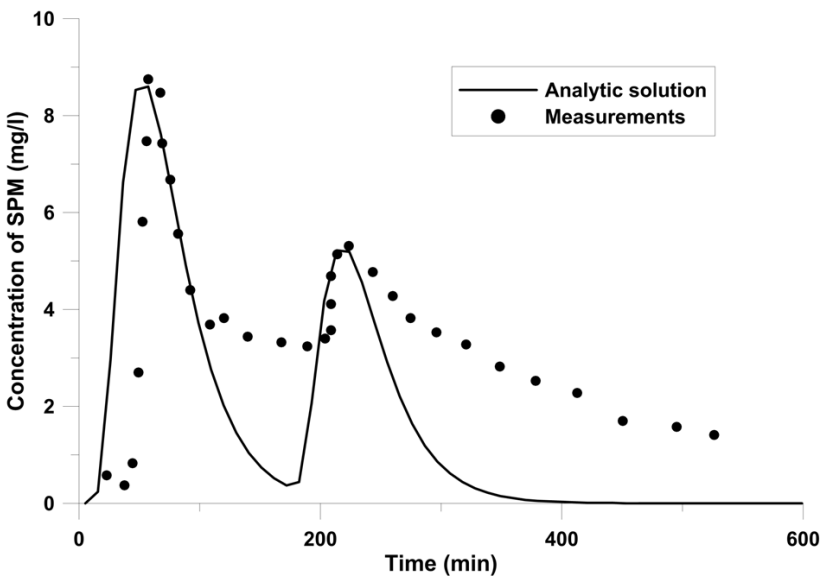

Fig. 8. Calculated and measured variation in SPM concentration with time for the second and third event in the Agnesberg landslide, using a dispersion coefficient of $D=230 \mathrm{~m}^{2} \mathrm{~s}^{-1}$.

The general features in the observed time variation of $c(t)$ at $x_{\mathrm{o}}$ are reproduced by Eq. (2), although the measured peak tends to be narrower and the asymmetry in time around $c_{\max }$ a bit larger.

This behaviour is even more pronounced when the second part of the landslide, containing two individual events, is simulated, as shown in Fig. 8 (concentration peaks aligned, as mentioned above). Also, after the second peak of the landslide (i.e. first peak in Fig. 8), a rather high concentration is observed before the third peak occurs, which is not reproduced by Eq. (2). The analytical solution yields a more rapid decay towards zero concentration (above the base level), before the next event occurs. The predicted total masses of suspended sediment involved in slides two and three were estimated to be $M=215000$ and $130000 \mathrm{~kg}$, respectively. Measurements indicated that the landslide encompassed a total surface area of approximately $8000 \mathrm{~m}^{2}$, which implies that about $0.6 \%$ of the landslide-released material was transported downstream as SPM, if a bulk density of $1600 \mathrm{~kg} \mathrm{~m}^{-3}$ (Larsson et al., 1994) is assumed and the slide depth is set to an average of about $7 \mathrm{~m}$ (the disturbed part of the rotational slide). This may be considered as a low suspended sediment ratio, but the slides taking place in the study area are dominated by rotational movements of coherent soil masses, meaning that the movements are classified as slides and not flows. The uppermost part of the moving mass consists of filling material and some sand above the clay. The sediment that comes into suspension originates most probably from material in the uppermost part that is more loosely packed, together with disturbed river bottom sediment.

Sensitivity tests were performed by varying the values of the main parameters in Eq. (2) and observing the response of the shape for $c(t)$ (the fitting procedure still ensured that $c_{\max }$ was obtained, which affected the value of $M)$. A larger value of $D$ produced a more asymmetric dis-

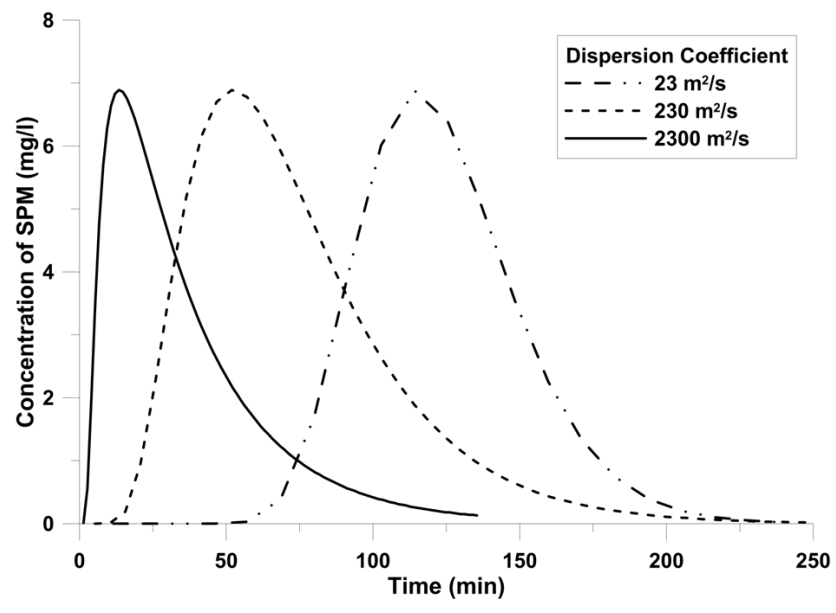

Fig. 9. Calculated variation in SPM concentration with time for the first event in the Agnesberg landslide, using different values on the dispersion coefficient.

tribution with a narrower peak, more similar to the measured $c(t)$. In contrast, a smaller $D$ yielded a more symmetric distribution, further away from the shape observed in the measurements. Regarding the initial mass of material released, larger $D$-values produced smaller $M$-values. Figure 9 illustrates how $c(t)$ responds to changes in $D$, where values 10 and $1 / 10$ times the value predicted by the theoretical formulas (i.e. $D=230 \mathrm{~m}^{2} \mathrm{~s}^{-1}$ ) were employed. The increase in asymmetry for $c(t)$ as $D$ increases is clearly seen in the figure, as well as how the arrival time for the peak at $x_{\mathrm{o}}$ decreases with increasing $D$. The more important advection becomes in relation to dispersion, the closer the time when $c_{\max }$ occurs will be to $x_{0} / U$, which is about $145 \mathrm{~min}$ (a value of $D=23 \mathrm{~m}^{2} \mathrm{~s}^{-1}$ approaches this limiting value). The value of the settling velocity $(w)$ had a pronounced effect on $M$, but less so on the shape of $c(t)$, where a smaller $w$-value implied a smaller $M$-value. For fine material, the settling velocity will be low and the influence on the concentration distribution negligible. Thomas et al. (2001) performed field measurements in two streams and found poor correlation between the calculated settling velocity and the deposition rate estimated from the collected data. Their assessment was that for sediment sizes below the range of 0.05 to $0.1 \mathrm{~mm}$, gravitational effects might be small.

In order to improve the agreement between the analytical solution to the ADE and the measurements, more complex solutions were investigated, including superimposing two solutions for different sediment particle sizes (i.e. settling velocities) and describing the release of material through the landslide by using a time-varying function rather than an instantaneous source (see Eq. 6). The latter approach could potentially describe the asymmetry in $c(t)$ better than Eq. (2), if a suitable function for the release of landslide material is employed (e.g. Eq. 5). The former approach, using for example two different sediment sizes, where one is coarser and 


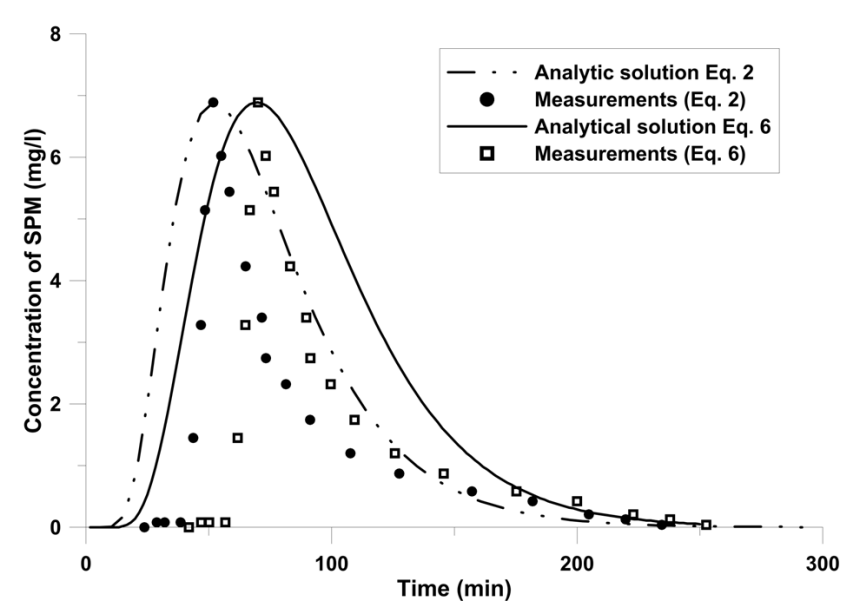

Fig. 10. Calculated and measured variation in SPM concentration with time for the first event in the Agnesberg landslide, using two different analytical solutions (Eqs. 2 and 6).

one finer, could produce a slower overall decay in $c(t)$ with higher concentrations at the tail, as was observed particularly after the second event (see Fig. 8).

The calibration process to determine the optimum value for $M$ in these more involved solutions, as well as the values of new parameters introduced (e.g. $\alpha$ ), becomes increasingly complicated and trial-and-error techniques must often be used. Figure 10 illustrates how well Eq. (6) can describe the first landslide in the Agnesberg event, where $M=190000 \mathrm{~kg}$ and $\alpha=0.001 \mathrm{~s}^{-1}$ were employed. The value of $\alpha$ (Eq. 5) was arbitrarily set and implies that the rate of mass transport has decreased to $15 \%$ of its initial value after $30 \mathrm{~min}$. The larger the value of $\alpha$ is, the closer Eq. (6) becomes to Eq. (2). The figure shows that introducing a finite release of material from the landslide using Eq. (5) yields limited improvement for the studied case: the tail of the calculated distribution slightly improves, but the rising phase is less well described (has a lower gradient) and the distribution around the peak is too wide.

Employing two different sediment sizes and superimposing the solutions obtained from Eq. (2), a more asymmetric shape of $c(t)$ may be simulated. However, more quantities emerge that need to be assigned values, unless information from the landslide is available. No particle grain size analyses were done in connection with the geotechnical analysis, but a good estimate for the clayey layer is a general particle size of $0.002 \mathrm{~mm}$. It is more difficult to estimate a general particle size for the second (main) and the third (retrogressive) events, which also contained filling material and possibly fluvial sediment, but it is reasonable to assume a particle size in the silt and sand fraction.

Employing two solutions implies that two initial sediment masses are released, resulting in more complex calibration with less generality in the results. Figure 11 illustrates the result from using two analytical solutions to represent the

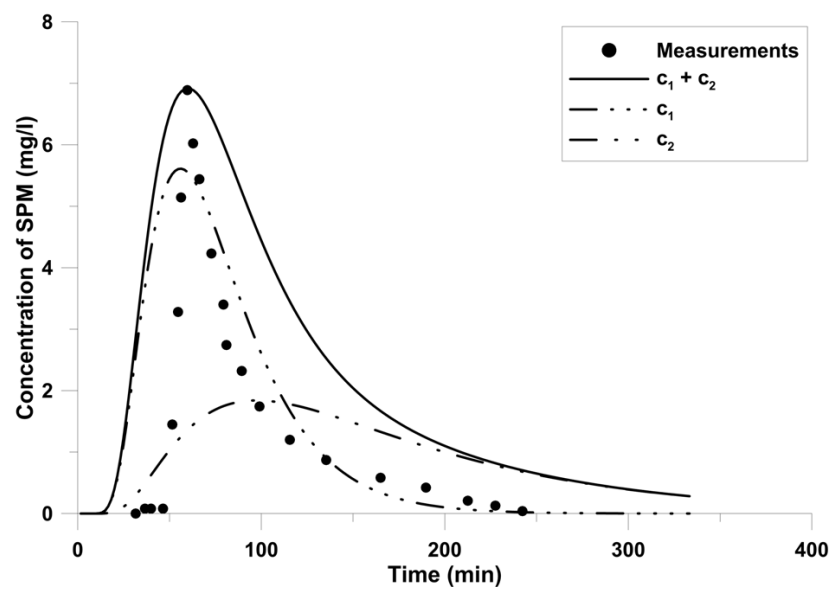

Fig. 11. Calculated and measured variation in SPM concentration with time for the first event in the Agnesberg landslide, using the combined effects of two different sediment sizes (coarse and fine silt).

release and transport of two sediments with the settling velocities of $0.002 \mathrm{~m} \mathrm{~s}^{-1}$ (associated with concentration $c_{1}(t)$ ) and $0.0002 \mathrm{~m} \mathrm{~s}^{-1}$ (concentration $c_{2}(t)$ ). The second sediment was given a much lower settling velocity in order to reproduce the extended tail observed in the measurements. This difference in settling velocities was reflected in the $M$ values obtained, which were $140000 \mathrm{~kg}$ and $7000 \mathrm{~kg}$, respectively. The overall shape of the distribution is well described, but the width is too large. Further manipulation of the settling velocities and the initial sediment mass released would yield better agreement, but would produce optimum values that are difficult to justify with regard to the conditions during the Agnesberg landslide. It may be easier to improve the agreement with measurements for events two and three using a solution involving two grain sizes, since the tail drops off at a markedly slower rate for these two slides compared to slide one.

\section{Discussion}

Different analytical solutions to the ADE were tested against the measured data from the shallow rotational, retrogressive landslide in clayey sediments that took place in 1993 on the Göta River, SW Sweden. To our knowledge, the registration of the impact on the river (suspended sediment) at a fresh water treatment plant downstream the landslide is one of the few of its kind in the world and unique for Sweden considering the low frequency of landslide events.

The classical analytical solution to the ADE for an instantaneous release of a fixed amount of material $(M)$ to a river produced satisfactory agreement with the observations. In the comparison with the data, almost all quantities were measured or estimated from available formulas except $M$, which was back-calculated from the measured maximum 
concentration. The asymmetric shape of the observed concentration distribution in time was reproduced by the solution, but the width of the distribution was overestimated. Also, for the second event (main slide), the decay rate for the measured concentration was lower than for the calculated. By modifying some of the main parameters, particularly the dispersion coefficient $(D)$, improved agreement is obtained, especially with regard to the width of the distribution. A larger $D$ will produce a narrower, more asymmetric distribution in line with the measurements. However, values of $D$ that yield the best agreement tend to be in a range that is non-physical.

More advanced solutions were employed to improve the agreement, including having a sediment release that is a function of time and employing different sediment grain sizes. In the former case, a slightly better fit was obtained for the tail of the distribution, but the width was still overestimated. Using two grain sizes with different settling velocities could also give better agreement for the tail-end of the distribution; again, the distribution was too wide. Furthermore, the difference in $M$ between the two grain sizes in the solution was significant and not very realistic.

The instantaneous release of sediment represents the phase when the soil mass moves into the water. The mobilisation of sediment by the landslide and the associated water motion generates a large amount of suspended sediments, initiating the transport of a sediment pulse and associated contaminants. When the concentration of suspended material exceeds the transport capacity of the water body, material starts to settle. This course of event is rapid and intense, and the contaminants are mobilized instantaneously with the suspended sediment. The long-term release and associated impact over longer distances occurs when the hydraulic regime returns to normal conditions and the suspended sediment settles in the far field. Long-term release of contaminants takes place through erosion of the run-out deposits during highflow events in the areas where sediment from the sediment pulse has settled. Most likely, also landslide scars may contribute additional contaminants, as they may lay bare and hence are exposed to diffusion, surface erosion (wind, water), and groundwater transportation; however we do not know their contribution to surface water quality.

Based on the solution presented here, it was estimated that only a small part of the displaced soil instantaneously came into suspension (about $0.6 \%$, which corresponds to $1-2 \%$ of the annual load) and that most of the material remained at the site in the river. This is also consistent with the observations, geotechnical investigations, and the dredging that later was undertaken to secure and clear the fare way. The cohesive forces in the clayey sediment and the shallowness of the landslide can probably explain this. Landslides in cohesive soils, such as rotational slides, translational slides, and slumps, often form the movement of coherent soil clods around a slip surface, in contrast to other mass movement such as debris falls, debris/mud/earth flows, and debris avalanches in friction soil, where particles lose contact, start to mix and be- have more like a liquid. Schwab et al. (2008) confirmed that only a fraction of material displaced by earth slides may be released to the sediment transport system but that a landslide should be considered as a point sediment source in the drainage basin. The instantaneous release of material, even though at a small rate, can reach several tons if the landslide is large enough, causing high concentrations in the water for a limited period of time. In river or lake waters that normally have low turbidity, such a sudden increase may cause harm to sensitive species and can also affect beneficial uses such as drinking water and swimming.

For the studied case, the landslide partly involved an industrial area with possible soil contamination from diffusive leakage or accidental spills. Sediment samples from the displaced soil and water taken some time after the landslide event indicated low contamination. However, no sampling was done in conjunction with the event. Instead, the results from the ADE solution where used, together with the sediment sampling, to estimate the probable instantaneous release of some metals and organics that could be associated with the release of suspended sediment. Even though there are uncertainties, the result indicates that several kilos of copper, lead, and chromium were released with each of the three slides, which correspond to between 0.1 and $0.5 \%$ of the total annual load for these substances. The total content of the contaminants in the displaced soil mass, the release rate, as well as the ratio between dissolved and particle bound contaminants, depending on the biogeochemical conditions, remain unknown and cannot be assessed.

The additional suspended sediment load and pollution load from the Agnesberg landslide may seem small, but then one has to keep in mind that this was a minor slide with a surface area less than $2 \%$ of the largest landslides in the area. Also, the soil contamination at the site was considered low (Naturvårdsverket, 1999). Nevertheless, it indicates that even small mass movements may affect the overall water quality, both in terms of chemical and physical properties, and that large slides do have the potential to yield large impact on water quality. This also demonstrates that landslides are possible sources of pollution and ought to be considered in the risk analysis for landslide hazard, as well as for contaminated land and water quality management.

Sedimentation, diffusive, advective, and break-down processes impact both concentrations and quantities that end up at a particular location (e.g. lake or estuary). Even though the slide itself does not involve areas with possible contamination, the run-out or generated impulse wave may cause damage to nearby industries or landfills (organic and inorganic pollutants), and fertilized agriculture (nutrients) or pastureland (E. coli from faecal). 


\section{Conclusions}

Data on turbidity collected in connection with a minor landslide into Göta River, SW Sweden, showed that the suspended sediment concentration downstream the release point exhibited a non-Gaussian variation with time, being strongly skewed. Even so, applying classical analytical solutions to the ADE for describing the effects of a landslide into surface water yields realistic predictions of the resulting concentration distribution in the river, if the initial conditions at the landslide site are known. Only a small part of the displaced soil instantaneously came into suspension (about $0.6 \%$, which corresponds to $1-2 \%$ of the annual load), and most of the material remained at the site in the river. Most parameter values in the ADE are straightforward to obtain through measurements at the site of interest, but some parameters may require detailed investigations, for example, the dispersion coefficient and the amount of sediment that is likely to go into suspension during a landslide. In general, the maximum concentration and the time when it occurs are the most important quantities to predict for analysis, risk assessment, and operational purposes. These two quantities are easily obtained from analytical solutions to the ADE. Overall it can be concluded from this study that even if the 1-D ADE represents a marked simplification of the complex processes that govern the transport and mixing of suspended material in the river in connection with a landslide, the equation provided a good description of the recorded data and it can be employed as a useful analysis tool coupled to existing risk assessment models. Based on the analysis of the data from the landslide into the Göta River, involving a part of an industrial site, it can also be concluded that mass movements are possible sources for the release of contaminants, and the ADE provides a good first approximation for the assessment of possible environmental risks, if the initial conditions can be specified. However, further and more detailed studies are needed to find more accurate descriptions of the transport processes. There is also a need to increase the knowledge on possible environmental consequences in the near and far field, in a short- and long-time perspective.

Acknowledgements. This study was financed by the Swedish Geotechnical Institute (SGI) and the national research council Formas (Grant 245-2007-786). The authors would like to thank all colleagues at the SGI for valuable information on landslides and landslide events in the Göta River area. We also would like to thank the staff at Göteborg Vatten (Alelyckan water supply plant) who have been very helpful and provided us with data from the time of the Agnesberg landslide. The comments by the anonymous reviewers are greatly appreciated.

Edited by: M. Gooseff

\section{References}

Abramowitz, M. and Stegun, I. A. (Eds.): Handbook of Mathematical Functions: With Formulas, Graphs, and Mathematical Tables, Dover Publications, New York, 1965.

Åkesson, M.: Mass movements as contamination carriers in surface water systems - Swedish experiences and risks, Master Thesis, Department of Geology, Lund University, Lund, 2010.

Åström, J., Pettersson, T. J. R., and Stenström, T. A.: Identification and management of microbial contaminations in a surface drinking water source, J. Water Health, 05, 67-79, 2007.

Atkinson, T. C. and Davis, P. M.: Longitudinal dispersion in natural channels: 1. Experimental results from the River Severn, U.K., Hydrol. Earth Syst. Sci., 4, 345-353, doi:10.5194/hess-4-3452000, 2000.

Bayer, T. M. and Linneman, S.: The nature and transport of the finegrained component of Swift Creek Landslide, Northwest Washington, Earth Surf. Proc. Land., 36, 624-640, 2011.

Bender, J., Mudesbach, C., and Jensen, J.: Synthetic hydrograph generator for reservoirs: Potential and limitations, EGU (European Geoscience Union General Assembly), Vienna, 2011,

Carslaw, H. S. and Jaeger, J. C.: Conduction of heat in solids, Clarendon Press, Oxford, 1959.

Caruso, B. S.: Risk-based targeting of diffuse contaminant sources at variable spatial scales in a New Zealand high country catchment, J. Environ. Manage., 63, 249-268, 2001.

Chanson, H.: Environmental hydraulics of open channel flows, Elsevier, 2004.

Crank, J.: The Mathematics of diffusion, Clarendon Press, Oxford, 1975.

Davis, P. M. and Atkinson, T. C.: Longitudinal dispersion in natural channels: 3. An aggregated dead zone model applied to the River Severn, U.K., Hydrol. Earth Syst. Sci., 4, 373-381, doi:10.5194/hess-4-373-2000, 2000.

Davis, P. M., Atkinson, T. C., and Wigley, T. M. L.: Longitudinal dispersion in natural channels: 2 . The roles of shear flow dispersion and dead zones in the River Severn, U.K., Hydrol. Earth Syst. Sci., 4, 355-371, doi:10.5194/hess-4-355-2000, 2000.

Deng, Z.-Q. and Jung, H.-S.: Variable residence time-based model for solute transport in streams, Water Resour. Res., 45, W03415, doi:10.1029/2008WR007000, 2009.

Deng, Z.-Q., Singh, V., P., and Bengtsson, L.: Longitudinal Dispersion Coefficient in Straight Rivers, 127, 919-927, 2001.

Deng, Z. Q., Bengtsson, L., Singh, V. P., and Adrian, D. D.: Longitudinal Dispersion Coefficient in Single-Channel Streams, J. Hydraul. Eng., 128, 901-916, 2002.

Fischer, H. B., List, E. J., Koh, R. C. Y., Imberger, J., and Brooks, N. H.: Mixing in inland and coastal waters, Academic Press, New York, 1979.

Goossens, H. and Zwolsman, J. J. G.: An evaluation of the behaviour of pollutants during dredging activism, Terra et Aqua, 62, 20-28, 1996.

GÄVVF: Fakta om Göta älv. En beskrivning av Göta älv och dess omgivning 2005. Göta älvs vattenvårdsförbund (The water quality association of Göta älv), 2006.

Göransson, G. I., Bendz, D., and Larson, P. M.: Combining landslide and contaminant risk: a preliminary assessment, J. Soil. Sediment., 9, 33-45, 2009.

Göransson, G. I., Persson, H., and Lundström, K.: Transport av suspenderat material i Göta älv (Transport of suspended 
sediments in the Göta river, Sweden), Swedish Geotechnical Institute, Linköping Delrapport 4 (Interim Report 4), available at: http://www.swedgeo.se/upload/Publikationer/Gota\% 20alvutredningen/GAU_delrapport_4.pdf (last access: 11 January 2012), 56, 2011.

Hamm, N. T., Dade, W. B., and Renshaw, C. E.: Fine particle deposition to porous beds, Water Resour. Res., 47, W11508, doi:10.1029/2010WR010295, 2011.

Heller, V.: Landslide generated impulse waves: Prediction of near field characteristics, PhD, Versuchsanstalt fur Wasserbay, Hydrologie und Glaziologie (VAW), Eidgenössische Technische Hochschule (ETH) Zurich, Zurich, 2008.

Huang, Y. H., Saiers, J. E., Harvey, J. W., Noe, G. B., and Mylon, S.: Advection, dispersion, and filtration of fine particles within emergent vegetation of the Florida Everglades, Water Resour. Res., 44, W04408, doi:10.1029/2007WR006290, 2008.

Jobson, H. E.: Predicting river travel time from hydraulic characteristics, J. Hydraul. Eng., 127, 911, doi:10.1061/(ASCE)07339429(2001)127:11(911), 2001.

Karwan, D. L. and Saiers, J. E.: Influences of seasonal flow regime on the fate and transport of fine particles and a dissolved solute in a New England stream, Water Resour. Res., 45, W11423, doi:10.1029/2009WR008077, 2009.

Kashefipour, S. M. and Falconer, R. A.: Longitudinal dispersion coefficients in natural channels, Water Res., 36, 1596-1608, 2002.

Lambe, T. W. and Whitman, R. V.: Soil Mechanics, SI Version, Series in Soil Engineering, John Wiley \& Sons, Inc., 1979.

Larson, M., Hanson, H., and Karus, N. C.: Analytical solutions of the one-line model of shoreline change, Coastal Engineering Research Center, US Army Corps of Engineers, Vicksburg, MSTechnical Report CERC-87-15, 1987.

Larsson, R., Ottosson, E., and Sällfors, G.: Agnesbergsskredet, Swedish geotechnical institute (SGI), Linköping, Sweden, Report No 44, 1994.

Mackey, B. H. and Roering, J. J.: Sediment yield, spatial characteristics, and the long-term evolution of active earthflows determined from airborne LiDAR and historical aerial photographs, Eel River, California, Geol. Soc. Am. Bull., 123, 1560-1576, 2011.

McCahon, C. P., Carling, P. A., and Pascoe, D.: Chemical and ecological effects of a pennine peat-slide, Environ. Pollut., 45, 275289, 1987.

Mouri, G., Shiiba, M., Hori, T., and Oki, T.: Modeling shallow landslides and river bed variation associated with extreme rainfallrunoff events in a granitoid mountainous forested catchment in Japan, Geomorphology, 125, 282-292, 2011.
Naturvårdsverket: Metodik för inventering av förorenade områden, Naturvårdsverket (Swedish Environmental Protection Agency), Stockholm Report 4918, 1999.

Ono, K., Akimoto, T., Gunawardhana, L. N., Kazama, S., and Kawagoe, S.: Distributed specific sediment yield estimations in Japan attributed to extreme-rainfall-induced slope failures under a changing climate, Hydrol. Earth Syst. Sci., 15, 197-207, doi:10.5194/hess-15-197-2011, 2011.

Paul, M. J. and Hall, R. O. Jr.: Particle Transport and Transient Storage along a Stream-Size Gradient in the Hubbard Brook Experimental Forest, J. N. Am. Benthol. Soc., 21, 195-205, 2002.

Reis, J. B.: The landslide in the Surma Khola Valley, High Mountain Region of the Central Himalaya in Nepal, Phys. Chem. Earth, Parts B, 25, 51-57, 2000.

Rhoades, E. L.: Quantifying bank erosion on the South River and its importance in assessing mercury contamination Master thesis, University of Delaware, Delaware, 82 pp., 2008.

Schwab, M., Rieke-Zapp, D., Schneider, H., Liniger, M., and Schlunegger, F.: Landsliding and sediment flux in the Central Swiss Alps: A photogrammetric study of the Schimbrig landslide, Entlebuch, Geomorphology, 97, 392-406, 2008.

Singh, S. K. and Beck, M. B.: Dispersion Coefficient of Streams from Tracer Experiment Data, J. Environ. Eng., 129, 539-546, 2003.

Sundborg, Å. and Norrman, J.: Göta Älv Hydrologi och Morfologi med särskild hänsyn till Erosionsprocesserna, SGU (Geological Survey of Sweden) SGU serie Ca. no. 43, 1963.

Ter-Stepanian, G.: Quick clay landslides: their enigmatic features and mechanism, B. Eng. Geol. Environ., 59, 47-57, 2000.

Thomas, S. A., Newbold, D. J., Monaghan, M. T., Minshall, G. W., Georgian, T., and Cushing, C. E.: The Influence of Particle Size on Seston Deposition in Streams, Limnol. Oceanogr., 46, 14151424, 2001.

USEPA: Sumas Mountain Asbestos, available at: http: //yosemite.epa.gov/r10/cleanup.nsf/sites/swiftcreek (last access: 28 July 2011), 2011.

van Mazijk, A. and Veling, E. J. M.: Tracer experiments in the Rhine Basin: evaluation of the skewness of observed concentration distributions, J. Hydrol., 307, 60-78, 2005.

Vreugdenhil, C. B. and Koren, B.: Numerical methods for advection-diffusion problems: Notes on Numerical Fluid Mechanics, Vieweg Braunschweig, 353-370 pp., 1993. 